\title{
Novel architectures and operation modes of Distribution Network to increase DG integration
}

\author{
N. Hadjsaid, Senior Member, IEEE, M.-C. Alvarez-Hérault Student Member, IEEE, R. Caire, \\ Member, IEEE, B. Raison ,Member, IEEE, J. Descloux, W. Bienia
}

\begin{abstract}
Nowadays, distribution networks are facing tremendous challenges. Actually, the opening of the energy market, the wish to preserve the environment and the reduction of fossil energy stocks have lead to use more and more distributed, renewable and local energy resources, such as wind and photovoltaic generators. These generating units are mostly connected to the distribution networks. With the increase of the penetration rate of these generation facilities, the traditional operation as well as planning of the concerned networks may need to evolve. In order to face this situation and offer increased network capabilities to support these new technologies, the distribution network has to switch to a flexible and smart network. To achieve these goals, two research paths are considered: the new architectures and the development of intelligent embedded systems. This paper deals with new architectures and particularly partially meshed distribution networks. It proposes a Monte Carlo algorithm as an efficient tool for analysing and assessing the relationship between grid architecture and DG penetration rate. Simulation results on a real urban French distribution networks have showed the effectiveness of the method with respect to grid planning. Particularly, it has demonstrated that evolving distribution grid architectures towards a partially and adapted meshed structure increases DG penetration level.
\end{abstract}

Index Terms--Distribution Network, Planning, Distributed Generation. Partially Meshed Grids, Monte Carlo Method

\section{INTRODUCTION}

$\mathrm{D}$ EREGULATION of electricity industry and the increasing environment concern of our modern societies foster the development of dispersed generations (DGs) and particularly renewable energy sources (RES). Most transmission networks are already saturated while it is more and more difficult to built new transmission lines. In this context, distribution networks may play a positive role by supporting transmission system through distributed generation injections at the distribution level provide they are well managed. Nevertheless a massive introduction of distributed generation could modify the behavior of distribution networks. Indeed, the distribution network was traditionally designed to deliver the energy to end users as a waterfall. Therefore, the rules used to plan those networks were mainly based on the existing load without taking into account foreseen production.

DGs are defined as generation units, usually smaller than

N. Hadjsaid, M.-C. Alvarez-Hérault, R.Caire and J. Desloux are with Grenoble Institute of Technology - G2Elab (Grenoble Electrical Engineering laboratory), France (hadjsaid@g2elab.inpg.fr). B. Raison is with University of Joseph Fourier and G2Elab. W. Bienia is with Grenoble INP and G-SCOP (bienia@grenoble-inp.fr).
10-12 MW (depending on the country), interconnected to distribution networks and located close to end user customers [1-2]. DG penetration particularly those based on renewable energies is more and more increasing for several reasons summarized in TABLE I.

TABLE I

REASONS OF THE DEVELOPMENT OF DG

\begin{tabular}{|c|c|}
\hline Law & $\begin{array}{l}\text { - The opening of the electricity market, } \\
\text { - Ecological constraints, } \\
\text { - Versatile rules, }\end{array}$ \\
\hline Existing network & $\begin{array}{l}\text { - Making good use of the existing network, } \\
\text { - Improving the quality and the continuity of } \\
\text { supply [3], }\end{array}$ \\
\hline Production & $\begin{array}{l}\text { - Installation costs more and more reduced [4], } \\
\text { - New technologies of DGs [5], } \\
\text { - New electronic power converters [6-7], } \\
\text { - Storage system associated to DGs [8], }\end{array}$ \\
\hline
\end{tabular}

Nevertheless, some DGs could not be able to take part to ancillary services that are mainly provided by centralized generation through the transmission network. Furthermore, a significant amount of DGs could raise negative impacts to the distribution network [9]. For instance, it can reverse the power flow, blind the protection scheme or even tap-changer transformers regulation could be disturbed. However, in the case of large DG penetration, they could and, even more, should provide ancillary services [10-11].

Many researches try to find innovative solutions to increase DG insertion in the distribution network. Some studies think about the optimal location and size of DGs ([12], [13], [14] and [15]) and others try to overcome the uncertainties regarding future production and consumption ([16], [17] and [18]). Finally, some reported research works have already pointed out the option of introducing the concept of looped network architecture in the distribution grid as a solution to DG penetration problems based on a given set of assumptions ([12], [19] and [20]). The results provided in reference [12] showed that this architecture is more open and cheaper to accommodate a significant amount of DG than the reinforcement of an existing radial architecture. The non served energy can be reduced and the power losses can be further minimized. But, it is a complex architecture and the mutation from a radial to a meshed structure implies a new protection scheme with new network equipments such as appropriate switches and circuit breakers, due to the increase of short circuit currents. 


\section{FUNDAMENTALS ON DISTRIBUTION NETWORK PLANNING}

This part describes the way distribution networks are planned by Electricité Réseau Distribution France (ERDF) and the main characteristics of encountered network structures.

\section{A. Planning criteria}

Electrical networks' planning is a complex process because it depends on many parameters more or less known and often hard to forecast (for instance investments, life duration of the materials, load and generation forecast, etc.). Many criteria have to be considered in order to select the best structures. TABLE II presents some of them.

TABLE II

PLANNING CRITERIA SYNTHESIS

\begin{tabular}{|c|c|c|}
\hline \hline Economic and technical & $\begin{array}{c}\text { Architecture } \\
\text { and exploitation }\end{array}$ & Environment \\
\hline Subscribed powers & $\begin{array}{c}\text { Max feeder } \\
\text { length }\end{array}$ & $\begin{array}{c}\text { Relief and } \\
\text { landscape }\end{array}$ \\
\hline $\begin{array}{c}\text { Max value of ground } \\
\text { short-circuit currents }\end{array}$ & $\begin{array}{c}\text { Conductor types } \\
\text { (overhead lines, } \\
\text { cables) }\end{array}$ & $\begin{array}{c}\text { Max and Min } \\
\text { temperatures }\end{array}$ \\
\hline Normal voltage values & Automation level & Storm frequency \\
\hline Protections & $\begin{array}{c}\text { Grounding } \\
\text { schemes }\end{array}$ & \\
\hline $\begin{array}{c}\text { Service quality level } \\
\text { linked with load } \\
\text { density }\end{array}$ & \\
\hline $\begin{array}{c}\text { Materials and persons } \\
\text { safety }\end{array}$ & \\
\hline Investment forecast & & \\
\hline \hline
\end{tabular}

For each presented architecture, the main switch will trip as soon as the fault is detected. In this case, the faulty part is located, isolated and customers are reenergized.

\section{B. The various network structures}

Depending on the network nature (rural, urban), the operation process is specific because the service quality constraints are different. In urban areas, load density is high and large amounts of energy have to be delivered over small distances. The maximum current allowed is very often the major constraint. On the contrary, in rural networks, the powers are often low but lengths of conductors are important. In this case, the voltage drop is usually the main constraint to respect. This point justifies the difference between the encountered network architectures.

In urban areas, two main architectures are recurring [21]. The first one is the secured feeders and its derivatives. The second one is the double supply (less used). Fig. 1 shows the secured feeder concept and its derivatives. In rural areas, radial architectures or interconnected primary feeders with many secondary feeders connected to them may be found.

For each structure, the judicious choice of remotely controlled switch makes it possible to increase the fault localisation, isolation and supply restoration capability (FLIR) [21].

\section{Planning principles}

In radial architectures and the absence of DGs, loads are supplied only by one way and such networks are characterized by an easy operation. In such architectures, loops and remotely "controlled normally open switches" are planned in case of failures to reenergize as soon as possible the customers.
In the secured feeder concept, a primary conductor connects two substations through almost all MV/LV substations. There are two possible ways of supply and the operation is still radial. Then the quality of service is good and quite competitive but the maximum feeder power is limited in order to supply all loads in case of failures.

According to the parameters monitored such as cost or quality of service, the secured feeder can evolve and lead to various structures. Indeed, the wire netting structure (grid) can be used if an excellent quality of service is expected; the looped structure is adapted in case of high loads brought together. The looped planning is claimed to have a very good quality of service but a very complex operation. All those evolutions of the secured network are seldom used because they are expensive and hardly to operate without smart automation and complex Distribution Management Systems.

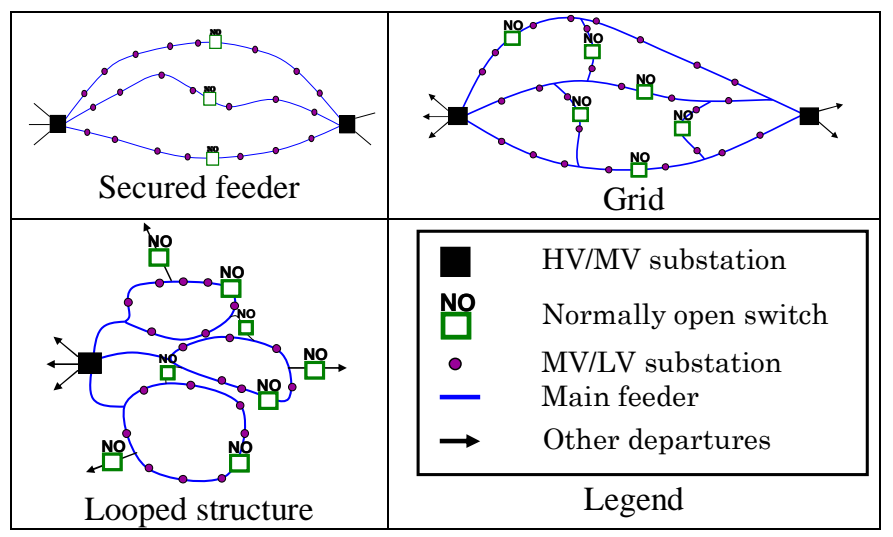

Fig. 1. Some urban architecture derived from "secured feeders"

In this paper, comparisons will be done on the secured feeder which is the most encountered network in urban French network.

\section{MESHING OPERATION TO INCREASE DG INSERTION RATE}

A. A stochastic approach for quantifying the relationship between network architecture and DG penetration rate

Quantifying the maximum DG penetration rate of a network is presently a crucial indicator both for grid and system operator performances. Indeed, it can enable planers to choose the best strategy to increase DG insertion in networks and thus fulfil regulatory objectives. However, the uncertainty on the amount of DG interconnection requests in the future, on their location and on their type (wind energy, solar energy, etc) makes it difficult to integrate them in traditional planning studies without taking a risk on choosing a strategy that turns out to be inappropriate in the future. That is why the Monte Carlo simulation is well suited to evaluate the capacity of a network to accept DGs because it simulates a large amount of possible cases. In addition, it gives an idea of the investment amount that may be needed to accommodate the future evolution of the network with an associated risk.

The rate of DG, $\tau_{\mathrm{i}}$ is defined as the percentage of the global consumption (P) energized locally by DG $\left(\tau_{\mathrm{i}}=1, \ldots, 100 \%\right)$. For each rate $\tau_{i}, n_{i}$ simulations are computed. During a 
simulation, the equivalent power $\mathrm{P}_{\mathrm{DG}}=\tau_{\mathrm{i}} \mathrm{x} \mathrm{P}$ is connected to the distribution network. Then the following steps describe how the size and the location of the DG are chosen.

1) Step 1: Choice and allocation of DGs

The number and the size of each DG are randomly generated with a uniform law until the total power $P_{D G}$ is reached. Then the different DG units are randomly connected to the nodes of the network.

\section{2) Step 2: Checking of constraints violation}

The voltage profile and the maximal allowed current in conductors are checked with a loadflow based on NewtonRaphson method [22]. Tap changers in transformers HV/MV substations are also taken into account in the loadflow. The loadflow calculation enables to check if the voltage at each node is kept within the allowed limits of $+/-5 \%$ of the nominal voltage. The currents of each line are also checked. The respect of all the constraints is called success. Successes are stored in a binary format.

\section{3) Step 3: Estimation of the probability of success}

The proportion of successes regarding the number of simulations done defines the probability of success. Finally the user can define a risk margin $\alpha$. This margin translates for example the fact that DGs would not provide their maximum power at the same time and new technologies such as current limiter exists. Fig. 2 illustrates the different steps for $20 \%$ DG insertion rate.

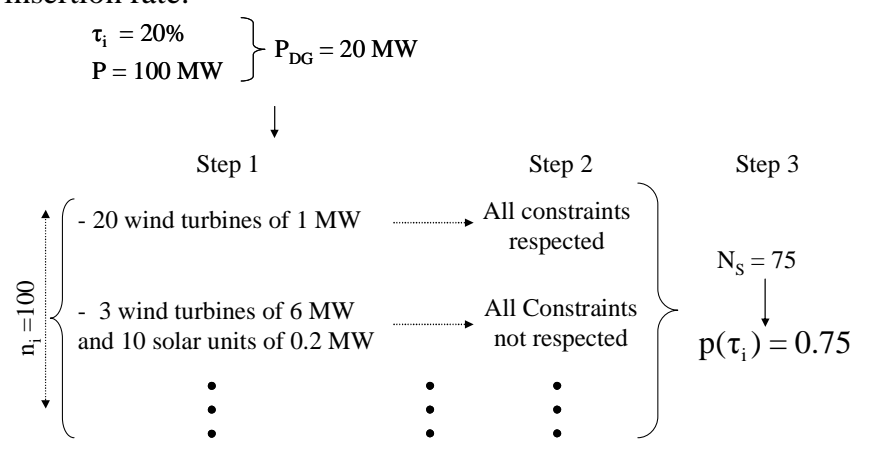

Fig. 2. Example of the Monte Carlo algorithm for $20 \%$ DG insertion rate

\section{B. Comparison of two strategies to increase DG insertion rate: reinforcement and meshing}

The real network that will be used has one substation that supplies 421 loads (total power of $62 \mathrm{MW}$ ). In the substation, there are 3 transformers of 36, 80 and 20 MVA equipped with on-load tap changers. Fig. 3 shows the structure of this network.

The first method to increase DGs insertion rate in the network is the reinforcement which is currently used by ERDF. It consists in detecting weak lines (with over-current) and replacing them by lines with larger gauges. The studied network is an urban network where the problems of overcurrent can mainly appear. Indeed, in urban networks, the load density is high. In the Monte Carlo algorithm, at each iteration, lines with over-current are memorized. At the end of the simulation, the lines that experienced significant over-current violations will need to be reinforced.

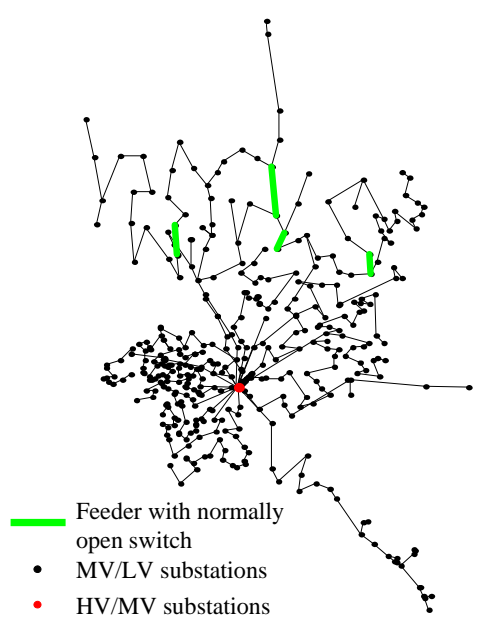

Fig. 3. Description of the real French urban network studied

Then, the technique chosen here to increase the meshing uses both geographic and technical criteria. First, the lines that have current flows higher than the maximum allowed current are identified (constraint violation). The principle is thus to relieve the constraint by building new lines near the constrained lines. For a given constrained line, the method used automatically finds the vertices that have only one neighbor. Then, two of them are selected regarding the distance to the constrained line. The new line joining those two vertices enables the constrained line to be discharged.

The results are depicted in Fig. 4. The meshing significantly increases DGs insertion rate. The curves show the probability of success to interconnect a given rate of DG (ratio between DG peak power and maximum load) for different scenarios. As expected, the actual architecture shows some weak points and some re-enforcement (chosen as described before) increase the probability of success. This re-enforcement is also compared with a partial meshing within few feeders (therefore with an equal investment). While considering a given risk, for instance $3 \%$, it is possible to quantify the added value of any given scenario with the difference between the curves at the probability of success of $97 \%$. Reliability studied based on the computation of confidence intervals gives the required number of simulations for each DG insertion rate. In our studies, this number is the number of nodes of the network.

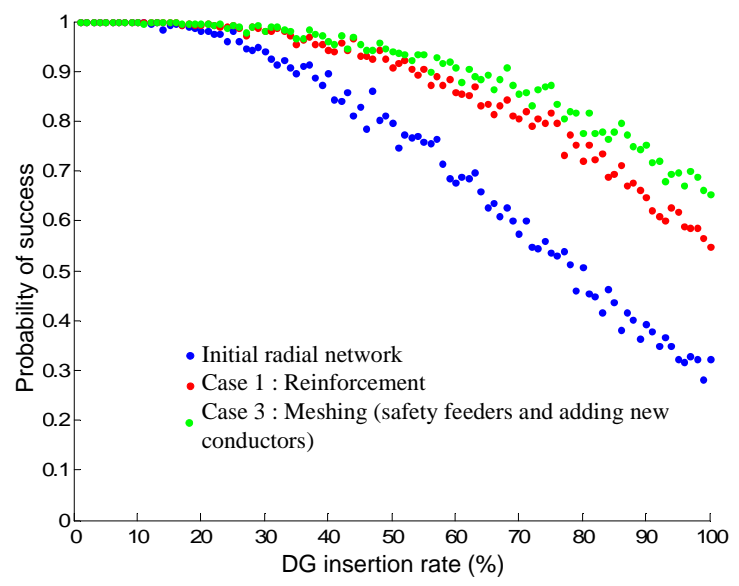

Fig. 4. Comparison between reinforcement and meshing 


\section{A NEW ARCHITECTURE TO INCREASE DG PENETRATION}

Part III points out the meshing operation as a way to increase DG in the network. In this section, partially meshed network architecture (hybrid structure) is therefore proposed.

\section{A. Description of the hybrid structure}

This new architecture, called the hybrid structure, is the combination of secured feeders and loops (see Fig. 5).

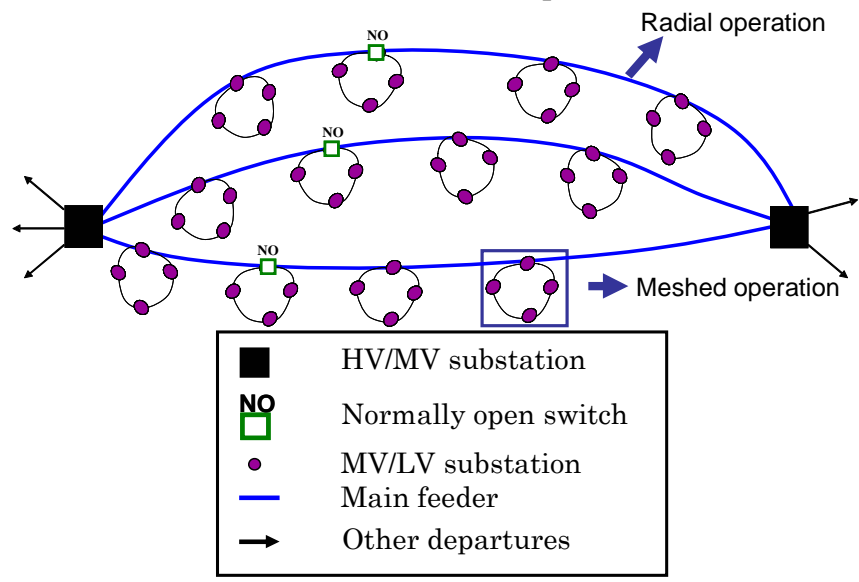

Fig. 5. Description of the hybrid structure

The main feeders of the hybrid structure are radially operated as in the secured feeder thanks to normally open switches. In the secured feeder, MV/LV substations are directly connected to the main feeders whereas in the hybrid structure, MV/LV substations are connected to the loops which themselves are connected to the main feeders. Those loops are operated meshed.

The Fig. 6 describes the protection scheme of each loop.

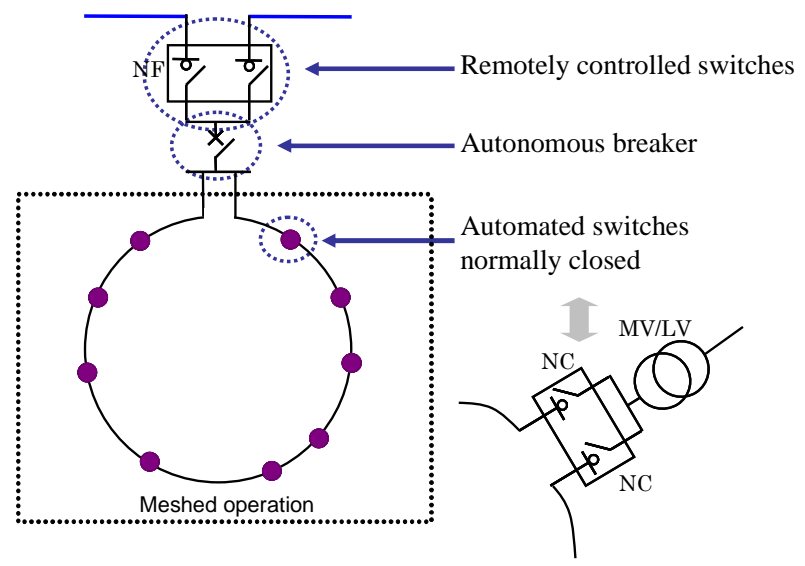

Fig. 6. Protection scheme of a loop

\section{1) Remotely control switches}

Each loop is connected to the main feeders by two remotely controlled switches. All those switches are normally closed except one to enable the radial operation of the main feeders. If a fault occurs on the main feeder, all the loops can be quickly reenergized by shifting the configuration of the remotely control switches.

\section{2) Autonomous breaker}

In case of a fault inside the loop, autonomous breaker disconnects the loop from the main feeders. Then, all the other customers are not affected by the fault. Cycles of connection and disconnection of the autonomous breaker helped by automated switches enable the fault inside the loop to be located. This is equivalent to the self closing processing of [23].

\section{3) Automated switches normally closed}

Each MV/LV substations can be connected to the loop with two automated switches normally closed. Four steps permit a fault inside the loop to be located and isolated. Fig. 7 illustrates those steps.

Step 1: The autonomous breaker trips then all the switches are opened.

Step 2: The loop is reenergized and the switches are successively closed in one way until the fault is encountered. Then, the autonomous breaker trips another time and the last closed switch is opened.

Step 3: The loop is reenergized and the switches are successively closed in the other way until the fault is encountered. Then, the autonomous breaker trips again and the last closed switch is opened.

Step 4: The loop can be reenergized because the two switches surrounding the fault are open and the others are closed.

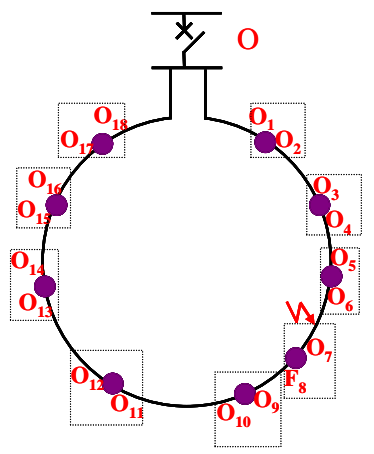

End of step 1

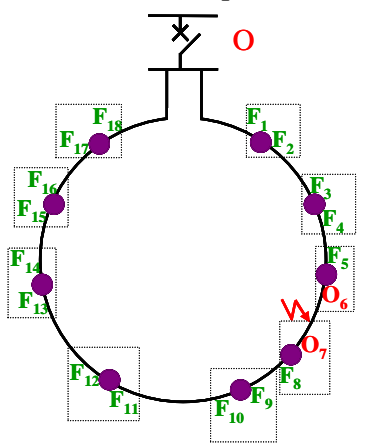

End of step 3

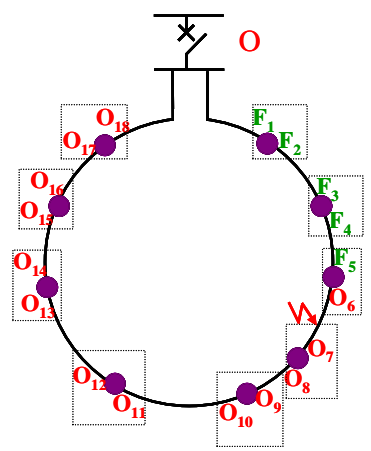

End of step 2

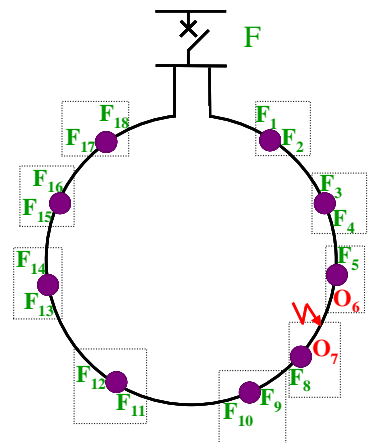

End of step 4
Fig. 7. Reenergizing procedure in case of a fault inside a loop

\section{B. Application on a real network}

The hybrid structure has been built on a real French urban network depicted in Fig. 8. It has two HV/MV substations and supplies $984 \mathrm{MV} / \mathrm{LV}$ substations that consume 151MW. The 
reliability of the hybrid structure has been studied thanks to the SAIDI (System average interruption duration index) computation. Also, the DG insertion rate has been evaluated thanks to the Monte Carlo algorithm.

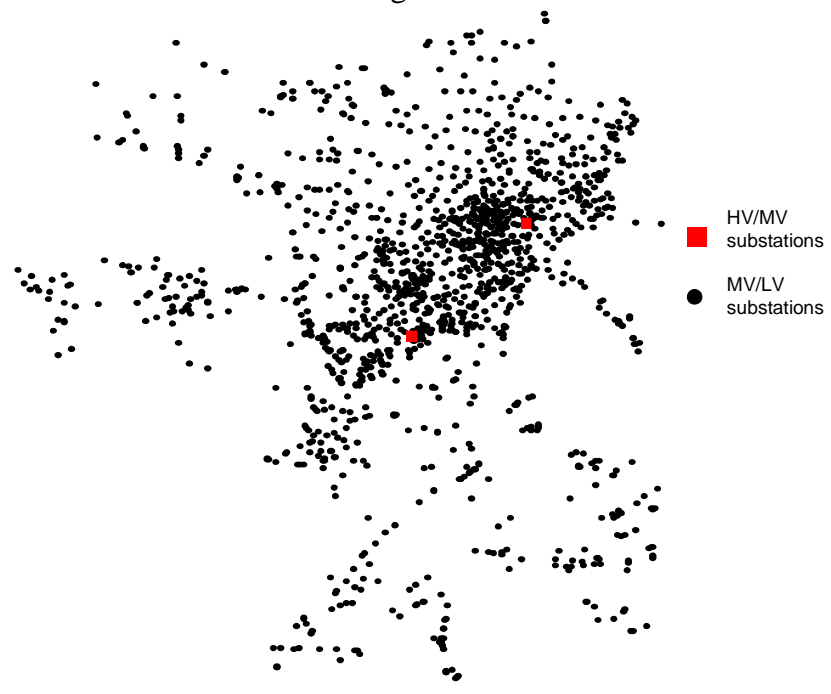

Fig. 8. Studied network

\section{1) Reliability}

Fig. 9 gives the SAIDI for the hybrid loop. The more loops there are the better the SAIDI will be. It can reach $1.93 \mathrm{~min}$ per customer per primary conductor. With a classic structure as the secured feeder, it can only reach $6 \mathrm{~min}$.

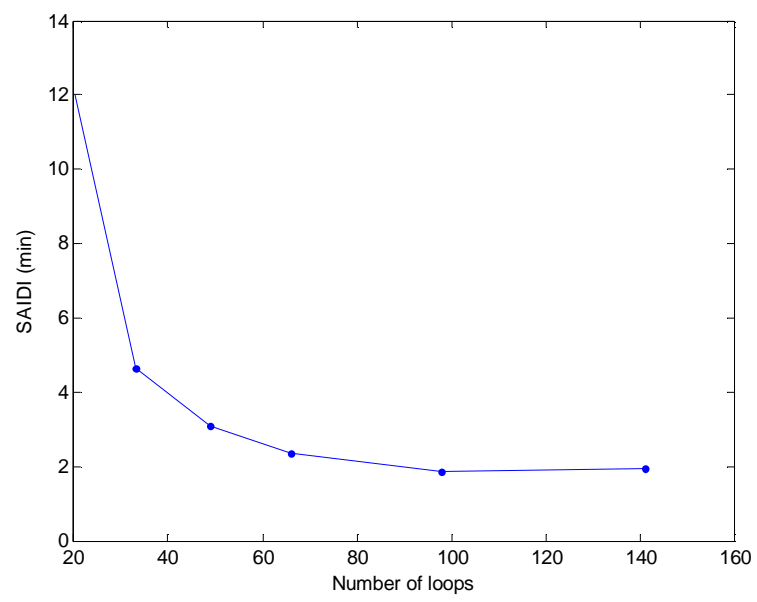

Fig. 9. Evolution of the SAIDI with the number of loops

\section{2) DG insertion rate}

Fig. 10 gives the evolution of the DG insertion rate regarding the number of loops. With a high number of loops, $63 \%$ of DG can be connected to the hybrid structure. The benefit of the hybrid structure is $16 \%$ higher than with the classic French structure: the secured feeder.

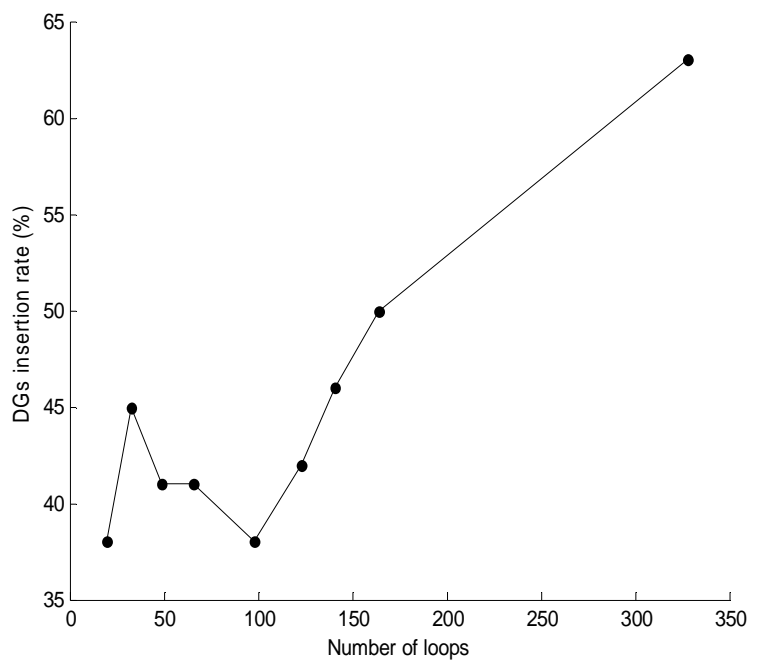

Fig. 10. Evolution of the DGs insertion rate with the number of loops

\section{CONCLUSION}

This paper shows that partially meshing the distribution network increases the maximum DG penetration rate in the network. The assessment was performed by using the Monte Carlo algorithm in the perspective of a stochastic approach. The proposed partially and appropriately meshed structure was achieved without any increase of the short-circuit currents. This algorithm suits very well because it enables all possible scenarios of insertion of DGs to be considered. Consequently, the results obtained are quite general. Also, meshing the network was highlighted as a better strategy to increase DG penetration rate than reinforcement, solution currently used by ERDF.

This studies enable to quantify the robustness of a given architecture with respect to the DG interconnection rate and to promote a new architecture partially meshed to increase DG insertion rate in the network. Thanks to its autonomous breaker and automation systems, it increases reliability by improving the SAIDI.

The way distribution system is built and operated is no longer adapted to the present day demands. It has to evolve towards new distribution systems to satisfy the goals of smart grids.

\section{REFERENCES}

[1] IEEE Standard for Interconnecting Distributed Resources with Electric Power Systems, Standards Coordinating Committee 21, July 2003.

[2] P. Abadie, «Journal officiel de la république française, arrêté du 23 avril 2008 relatif aux prescriptions techniques de conception et de fonctionnement pour le raccordement à un réseau public de distribution d'électricité en basse tension ou en moyenne tension d'une installation de production d'énergie électrique », 25 avril 2008.

[3] B. Enacheanu, R. Caire, B. Raison, O. Devaux, W. Bienia, N. Hadjsaid, "Radial Network Reconfiguration Using Genetic Algorithm Based on the Matroid Theory", IEEE Transactions on Power Systems, Vol. 23, No 1, February 2008, pp. 186-195.

[4] H. L. Willis, W. G. Scott, "Distributed Power Generation", Marcel Dekker, New York, 2000.

[5] A. Teninge, D. Roye, S. Bacha, J. Duval, "Low voltage ride-through capabilities of wind plant combining different turbine technologies", 
Power Electronics and Applications, 2009. EPE apos;09. 13th European Conference on. Volume, Issue , 8-10 Sept. 2009 Page(s):1 - 9.

[6] N. Laverdure, D. Roye, S. Bacha, R. Belhomme, "Mitigation of voltage dips effects on wind generators", EWEC'04, London, 2004

[7] University of Strathclyde, "Distributed generation with high penetration of renewable energy sources", European project DISPOWER, Deliverable 9.3, December 2005.

[8] P.D Nguyen Ngoc, T. Pham, S. Bacha, D. Roye, "Optimal operation for a wind-hydro power plant to participate to ancillary services", Industrial Technology, 2009. ICIT 2009. IEEE International Conference on, Volume, Issue, 10-13 Feb. 2009 Page(s):1 - 5.

[9] N. Hadjsaid, J.-F. Canard, F. Dumas, "Dispersed generation impact on distribution networks", Computer Applications in Power, IEEE, Volume 12, Issue 2, April 1999 Page(s):22 - 28.

[10] T. Ackermann, V. Knyazkin, "Interaction between Distributed Generation and the Distribution Network: Operation Aspects", Transmission and Distribution Conference and Exhibition 2002.

[11] J. A. Peças Lopesa, N. Hatziargyriou, J. Mutale, P. Djapic and N. Jenkins, "Integrating distributed generation into electric power systems: A review of drivers, challenges and opportunities", Electric Power Systems Research, Volume 77, Issue 9, July 2007, Pages 1189-1203, Distributed Generation.

[12] G. Celli, F. Pilo, G. Pisano, "Meshed Distribution Networks To Increase the Maximum Allowable Distributed Generation Capacity" , accepted for CIGRE Symposium 2005, Athens (Greece), April 2005.

[13] G. Celli, F. Pilo, "Optimal Distributed Generation Allocation in MV Distribution Networks", IEEE 2001.

[14] G. Celli, E. Ghiani, S. Mocci, F. Pilo, "A multiobjective evolutionary algorithm for the sizing and siting of distributed generation", IEEE 2005.

[15] V. F. Martins, C. L. Tancredo Borges, "Distribution systems expansion planning considering the exploitation of distributed generation by a multi-objective genetic algotithm", CIRED 2007.

[16] G. Celli, F. Pilo, "MV network planning under uncertainties on Distributed Generation penetration", IEEE 2001.

[17] G. Celli, S. Mocci, F. Pilo, R. Cicoria, "Probabilistic optimization of MV distribution network in presence of distributed generation", IEEE 2002.

[18] B. Cannas, G.Celli, F. Pilo, "Optimal MV distribution networks planning with heuristic techniques", IEEE 1999.

[19] G. Celli, F. Pilo, G. Pisano, V. Allegranza, R. Cicoria, "Distribution network interconnection for facilitating the diffusion of distributed generation", CIRED 2005.

[20] G. Celli, F. Pilo, G. Pisano, V. Allegranza, R. Cicoria, A. Iaria, "Meshed vs.radial MV distribution network in presence of large amount of DG", IEEE 2004.

[21] J. Northcote-Green, R. Wilson, "Control and Automation of Electrical Power Distribution Systems", Taylor \& Francis Group, 2007.

[22] P. Kundur, «Power System Stability and Control », EPRI editors, ISBN13: 978-0070359581, 1er mars 1994.

[23] S. Koizumi, M. Okumura, T. Yanase, "Application and Development of Distribution Automation System in TEPCO", Power Engineering Society General Meeting, 2005. IEEE, Volume, Issue , 12-16 June 2005 Page(s): 2429 - 2435 Vol. 3.

\section{BIOGRAPHIES}

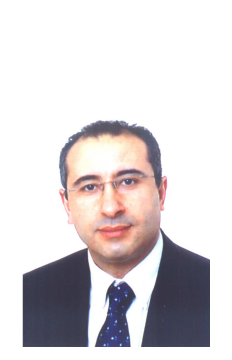

Nouredine Hadjsaid received $\mathrm{PhD}$ and the "Habilitation à Diriger des Recherches" degrees from the Grenoble Institute of Technology (Grenoble InP) in 1992 and 1998 respectively. He has served as an assistant professor at the Ecole Nationale Supérieure d'Ingénieurs Electriciens de Genoble and the Laboratoire d'Electrotechnique de Grenoble from 1992 to 2000 . He has been appointed as a full professor at the same Institute since 2000 . He is presently the General Director of a common research center between EDF, Schneider Electric and INPGrenoble (IDEA) on distributed generation and future electrical distribution systems.

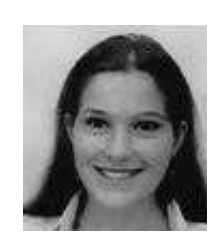

Marie-Cécile Alvarez-Hérault was born in Limoges in France, on April 5, 1983. She received her Engineering Diploma, her Master degrees and her Ph.D. degrees in electrical engineering from the Grenoble INP, France, in 2007 and 2009. Her research interest is located on new architectures and exploitation of distribution networks in presence of distributed generation. Dr AlvarezHérault is with Grenoble Institute of Technology.

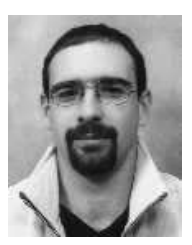

Raphael Caire (M'04) received his DEA from INPGrenoble in 2000. He was working in Power Electronic field, in France at the Laboratoire de Génie Electrique de Grenoble (LEG) and in USA at the Center of Power Electronic System (CPES). He is now associate professor at Grenoble INP-ENSE3-G2Elab. His research is centered on the impacts, production control of dispersed generation on distribution system and critical infrastructures. Dr Caire is with Grenoble Institute of Technology.

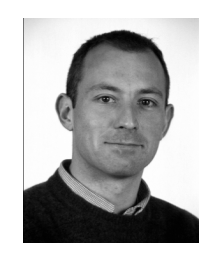

Bertrand Raison (M'03) was born in Béthune, France in 1972. He received his M.S. and Ph.D. degrees in electrical engineering from the Grenoble INP, France, in 1996 and 2000. He has joined since 2001 the Grenoble INP-ENSE3-G2Elab as associate professor. His general research interests are fault detection and localization in electrical systems. Pr Raison is with Joseph Fourier University, Grenoble.

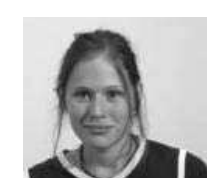

Justine Descloux is an engineering student at the ENSE3 from Grenoble INP. She will receive her Engineering Diploma and her Master degrees in electrical engineering in July 2010. Ms Descloux is with ENSE3.

Wojciech Bienia received his Master degree in Mathematical Applications from Silesian Polytechnic School in Poland in 1976 and his PhD degree in Oriented Matroids Theory from University PARIS VI in 1985. Since 1988, he is associate professor at the ENSIMAG (Computer Science and Applied Mathematics School of Grenoble)-Grenoble INP, where he belongs to the G-SCOP (Sciences of Conception, Optimisation and Production) group. His present research interests are Operational Research and Combinatorial Optimisation. Dr Bienia is with Grenoble Institute of Technology. 